\title{
Research on the Construction of Programming Curriculum Group in Independent Colleges
}

\author{
Guang Hui Feng ${ }^{1, a,{ }^{*}}$, Xiao Ling $\mathrm{Mi}^{2, \mathrm{~b}}$ \\ ${ }^{1}$ Department of computer science, Zhuhai College of Jilin University, Zhuhai, Guangdong, China \\ 2 Public English Education, Zhuhai College of Jilin University, Zhuhai, Guangdong, China \\ a14139339@qq.com, b445817361@qq.com
}

${ }^{*}$ Corresponding author

\begin{abstract}
Keywords: Curriculum group, Talent cultivation, Network learning platform, Decision-making tree, C4.5.
\end{abstract}

\begin{abstract}
Specific to the characteristics of programming curriculum, such as similar content, close contact, mutual promotion and supplementation, and belonging to the same ability training category, this paper takes the construction of the programming curriculum group of Zhuhai College of Jilin University as the background to discuss the principles, methods, and existing problems of the curriculum group construction in independent college.
\end{abstract}

\section{Introduction}

In recent years, with the rapid development of computer technology, and its penetration of application into all walks of life, it puts forward new demands on the quality of computer professionals. The independent college is a new type of undergraduate education, which comes into being due to the promotion of the modernization of China's economic construction and the popularization of higher education according to the characteristics of Chinese university cultivation. The goal of talent training for independent colleges is not to place emphasis on academic talents of theoretical research, but to cultivate applied talents urgently needed socially. Such talents should have a certain theoretical foundation and master practical skills to meet the needs of the employment market for applied talents. The goal of talent training in computer specialty in independent colleges should take cultivating students' spirit of innovation and practical ability as the core, strengthening students' quality education, emphasizing students' personality development, regarding quality improvement as core task. Besides, the independent colleges need to work closely with enterprises to cultivate applied talents, so as to play its due role in regional economy and social development.

Although colleges and universities attach great importance to the construction of excellent curriculums in computer specialty, they are mostly confined to single curriculum, showing obvious limitations and deficiencies in realizing the goal of talent cultivation. The construction of programming curriculum group has gradually become an essential condition in cultivating high-quality applied talents for computer specialty, and also an important link in specialty construction.

\section{The Principle for The Construction of Programming Curriculum Group}

The programming curriculums should be redesigned, replaced and integrated into organic assembly. It can not only coordinate the links between related curriculums but also highlight the characteristics of each curriculum, on the basis of optimizing educational resources, to obtain overall advantages to create superior disciplines. This overall principle this process should follow is: 
Firstly: People-oriented. Form a student-centered, teacher-oriented thought, to give full play to students' subjective initiative and creativity and guide them to positively explore and actively discover things.

Secondly: Relevance. Programming curriculum group includes: $\mathrm{C} / \mathrm{C}++$ language program design, C\# OOP (object-oriented programming), JAVA OOP, data structure, algorithm design and analysis, database system, etc. The models, methods and steps for solving problems between the entire curriculum systems have similarity and gradualness.

Thirdly: Integration. It reflects the significance of mutual curriculums in the programming curriculum groups. Students are enabled to better grasp the relation between a curriculum and other curriculums as well as the entire curriculum group, so as to achieve the effect of $1+1>2$, and to promote students to do cognitive transfer flexibly.

Fourthly: Innovation. That is to pay attention to the reform and innovation of teaching methods and teaching models, meanwhile, to keep up with the times and satisfy the continuous demands of society and enterprises for compound application talents.

\section{The Construction Content of Programming Curriculum Group}

\subsection{Construct scientific curriculum group}

In view of the objective of cultivating applied talents in independent colleges, considering the employment characteristics comprehensively, the conditions for running schools, and the situation of teachers in computer specialty, a programming curriculum group has been constructed. The curriculum covered by programming curriculum group in computer specialty is shown in Figure 1, which strives to build an excellent curriculum group with reasonable structure, clear level, well-ordered connection and mutual complement.

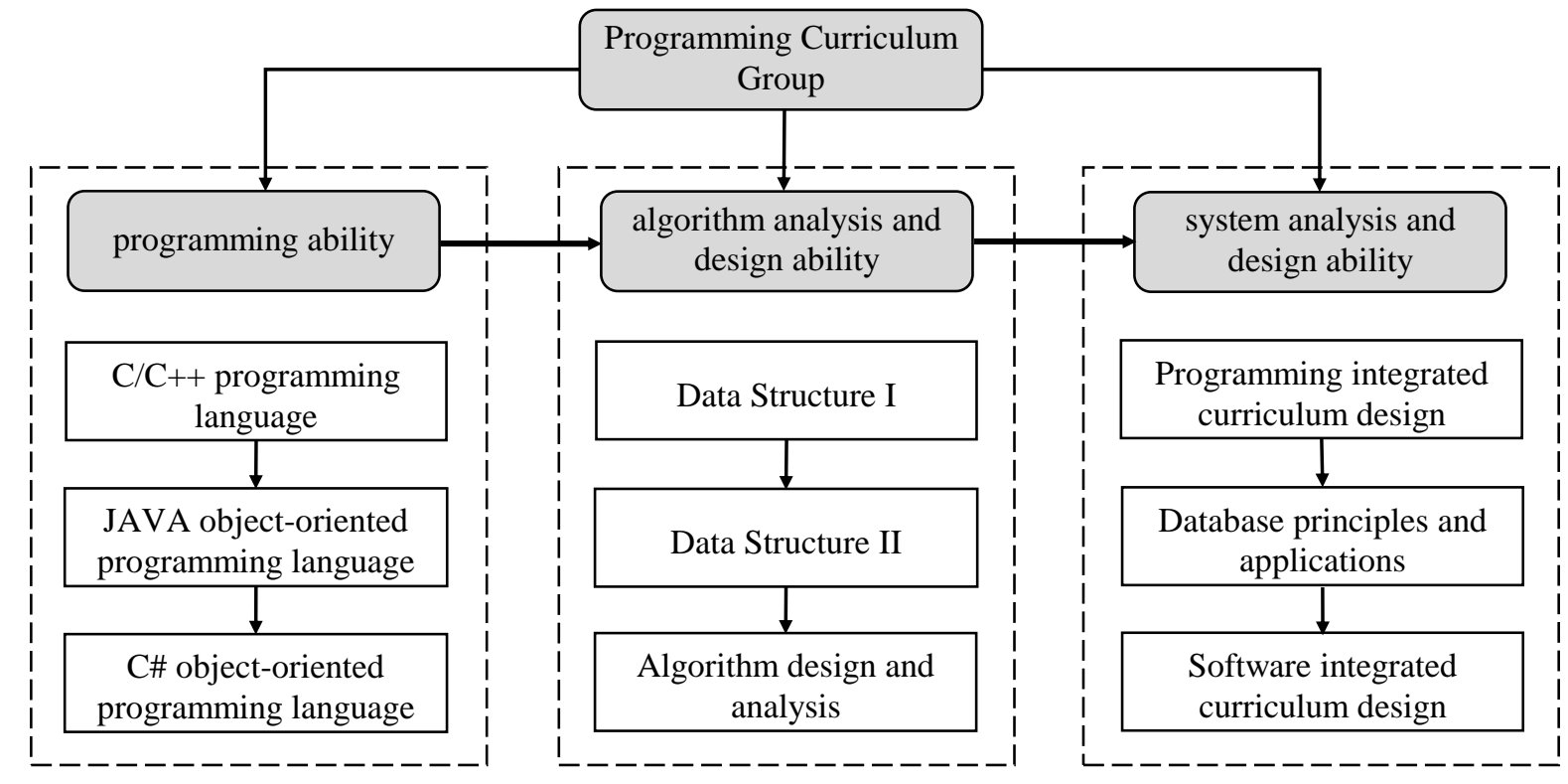

Fig. 1. Programming Curriculum Group

There are three types of curriculum in the curriculum group: the basic programming curriculums such as $\mathrm{C} / \mathrm{C}++$ Language Programming and JAVA Object-Oriented Programming focusing on the mastery of programming rules and the practice of programming ability. Some series curriculums like Data Structure place extra emphasis on the improvement of students' analysis and design capabilities. What's more, the comprehensive practice-training curriculums like Programming Basis and Integrated Curriculum Design and Database Principles and Applications focus on cultivating students' system analysis and design ability. 


\subsection{Reform Existing Teaching Model}

Being application-oriented, by combining with the actual demands of enterprises, adjusting the focus of curriculum, and adopting complex and diverse teaching models, it makes the teaching content, teaching methods and teaching means more conformable with the cognitive laws and psychological characteristics of applied talents cultivation, which can guide students to learn automatically for the purpose of combining knowledge transfer, ability training, quality education. The curriculums in the curriculum group can be divided into the following three categories and teach in different ways:

C/C++ Language Programming, C\# Object-Oriented Programming, Java Object-Oriented Programming and other language curriculums focus on the improvement of students' programming capabilities, which adopts the teaching mode of Oriented in on-site programming demonstration, supplemented by multimedia courseware and books.

Curriculums such as Data Structure, Algorithm Design and Analysis, and Database, which are based on students' solid programming skills, enable students to master how to organize, store and process data effectively, and correctly design algorithm as well as analyze and evaluate on the algorithm. The teaching of this part adopts a combination of theory teaching, case teaching, and project-driven teaching.

Programming Basis and Integrated Curriculum Design belongs to the engineering practice-training class. It adopts the flipped classroom model, for which students form project teams, so as to train and cultivate students' engineering practice abilities, interpersonal skills, teamwork spirit, professional ethics and character, and in the end to improve students' comprehensive quality.

\subsection{Launch School-Enterprise Cooperation and International Cooperation}

Through establishing a computer collaborative practical teaching platform with cooperative enterprises, the lack of basic training of students' engineering practice and the deficiency of students' ability of actually solving engineering problems both have been settled. Enterprises provide practical training programs and assist comprehensive practical training and graduation design guidance. By participating in enterprises' actual development projects, gaining real development and practical experience and improving the ability of technology application, autonomic learning and innovation, students achieve the purpose of pre-post ability training, intensifying and training.

We should actively promote the Enterprise engineers enter classroom teaching, while full-time teachers go to enterprises for training, which has not only improved teacher's engineering practice experience, but also promoted students' hands-on ability and employment competitiveness.

By Uniting with programming language curriculums in foreign universities and colleges, and introducing advanced foreign teaching concepts and knowledge systems into the curriculum, the school's teaching system will be constantly improved. Since the English level of most students in computer specialty still need improving, the Chinese teaching assistant need to assist translation as the foreign teacher is giving speech, to help students develop their language and comprehension ability.

\subsection{Introduce Informationized Learning Platform}

Up to December 2017, the number of Internet users in China reached up to 772 million, and the Internet penetration rate was $55.8 \%{ }^{[1]}$. Over $99 \%$ of our students have computers, smart phones, tablet computers and other electronic devices. The Internet, especially the popularity of the mobile Internet, has provided us with equipment protection for network learning and mobile learning. Moreover, network learning and mobile learning can solve the problem of limited space and time in traditional teaching, enabling teaching and learning to be conducted anytime and anywhere, and launching 4A learning mode ${ }^{[2]}$ of Anyone, Anytime, Anywhere, Any-style. To this end, we have provided a network autonomous learning platform which makes up a complete learning process combining classroom teaching with practical teaching ${ }^{[3]}$, to strengthen students' ability to think independently and learn autonomously. The design of learning process is shown in Figure 2. 


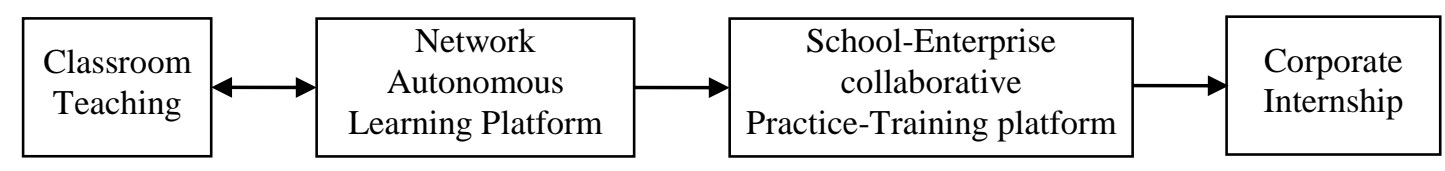

Fig. 2. The design of learning process

The main functions of network autonomous learning platform:

Through learning platform, teachers can manage curriculums, store curriculum documents (curriculum description, syllabuses, teaching schedules, courseware, etc.) and curriculum resources (self-test question bank, knowledge point videos, etc.), and also publish curriculum information, conduct questionnaire survey, publish curriculum test, view statistical data of students' learning condition, tutor online, etc.

Students are able to independently select time periods for learning, preview and collate knowledge points, watch teaching knowledge points' videos, check knowledge points, test after-class assignments, chapter tests, and comprehensive tests. They can also manage learning plans and learning progress, review learning status at stages (homework completion status, test situation, examination situation, participation in the forum, etc.), so as to have a comprehensive grasp of their own learning process, timely adjustment of learning focus and progress to improve learning efficiency and learning outcome.

\subsection{Establish the Assessment Based on Decision-Making Tree and Evaluation Mechanism}

Since most curriculums in the programming curriculum group use the network learning platform, special emphasis is placed on the monitoring of students' learning process, and the analysis of learning trajectories and learning effects. On this basis, students' curriculum e-portfolio is established, which can provide data for learning summary, predictions and recommendations ${ }^{[4]}$.

Table 1. Grade Table Sample

\begin{tabular}{lllll}
\hline No. & A & B & C & D \\
\hline 1 & 1 & 1 & 1 & 1 \\
\hline 2 & 1 & 0 & 1 & 1 \\
\hline 3 & 1 & 1 & 0 & 0 \\
\hline 4 & 0 & 1 & 0 & 1 \\
\hline 5 & 0 & 1 & 1 & 1 \\
\hline 6 & 1 & 1 & 1 & 1 \\
\hline 7 & 1 & 0 & 0 & 0 \\
\hline 8 & 1 & 0 & 1 & 1 \\
\hline 9 & 0 & 0 & 0 & 0 \\
\hline$\ldots$ & $\ldots$ & $\ldots$ & $\ldots$ & $\ldots$ \\
\hline Pass & 20 & 16 & 16 & 18 \\
\hline Fail & 8 & 12 & 12 & 10 \\
\hline
\end{tabular}

The model for assessment of learning effectiveness and evaluation model is expanded according to subjects and knowledge points. For example, the leading curriculums of data structure are discrete mathematics, C++ language program design. Through decision-making tree's analysis on the association degree between knowledge points, the $\mathrm{C} 4.5$ algorithm ${ }^{1}$ has been applied to generate decision-making tree and decision rules. Taking one administrative class of 28 people as an example, the meanings of the fields in Table 1 are as follows: A: discrete mathematics final assessment, B: comprehensive test in $\mathrm{C}++$ structured programming, $\mathrm{C}$ : comprehensive test in $\mathrm{C}++$ object-oriented programming, D: Linear list unit test of data structure; field value: 0 means fail, 1 means pass.

\footnotetext{
${ }^{1} \mathrm{C} 4.5$ algorithm is a classic algorithm of decision-making tree technology. The information gain rate is used as classify and evaluate the function to select the optimal attribute.
} 
After pruning the generated decision-making tree, an optimal decision-making tree is obtained. As shown in Fig. 3, according to this decision-making tree, the classification rule is generated in the form of IF...THEN..., and each path from the root node to the leaf node can generate a classification rule. The decision-making tree shown in Fig. 3 generates the following three rules:

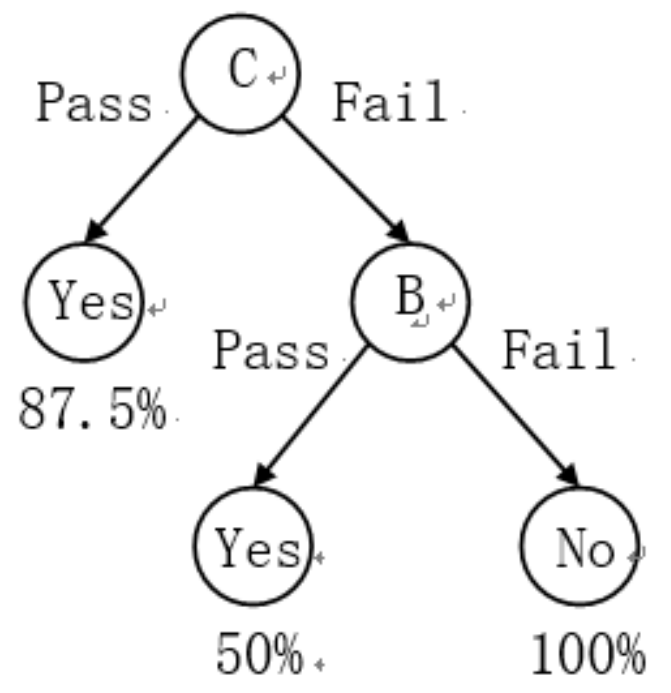

Fig. 3. Decision-Making Tree Model for Students' Grade

(1) If (comprehensive test in $\mathrm{C}++$ object-oriented programming gets passed) Then Linear list unit test of data structure $=$ accuracy rate $87.5 \%$ of pass.

(2) If (comprehensive test in $\mathrm{C}++$ object-oriented programming fails) and (comprehensive test in $\mathrm{C}++$ structured programming gets passed) Then Linear list unit test of data structure $=$ accuracy rate $50 \%$ of pass.

(3) If (comprehensive test in $\mathrm{C}++$ object-oriented programming fails) and (comprehensive test in $\mathrm{C}++$ structured programming fails) Then Linear list unit test of data structure $=$ accuracy rate $100 \%$ of pass.

Through analysis of the above decision rules, it is found that students' learning effect of the C++ object-oriented part directly affects the learning effect of data structure linear list, while the discrete mathematics has almost no effect on the learning of data structure linear list. In order to improve students' learning effect of the subsequent chapters of data structure, teachers should promptly remind and supervise students to consolidate the foundation of $\mathrm{C}++$. In the assessment and evaluation of curriculums within the curriculum group, by using the decision-making tree model to classify and predict students' achievements, we can obtain some useful knowledge ${ }^{[5]}$. These knowledge will help guide teachers' teaching work in the future, and provide a basis for students' following learning, and all in all it to achieves the goal of improving teaching quality.

\section{The Existing Problems in The Construction of Programming Curriculum Group}

The construction of curriculum group is a development trend of college curriculum construction and reform. At present, there are few examples which can be referenced. The programming curriculum group is all important professional basic curriculums, involving a large number of teachers, and a variety of hierarchical structures. Thus, it needs for coordination and efforts of many parties, such as overcoming difficulties in practical work, venturing practice, reforming teaching modes and teaching methods, adjusting teaching plans and teaching contents, and absorbing new technologies to meet business needs and to advance with the times.

In addition, the construction of a complete curriculum group requires three-dimensional textbooks with interrelated and coordinated contents. The three-dimensional textbooks should take digital learning as the core, compatible with modern teaching methods such as paper-printing textbooks, 
multimedia, teaching websites, and online videos. The existing textbook system does not meet the demands of curriculum group construction. Therefore, it is necessary to speed up the construction of textbook and curriculum group.

\section{Summary}

The construction of the computer programming course group of the independent college should be application-oriented and promote the construction of the curriculum with the target of sharing, thus optimizing instructional effects and students' comprehensive application ability.

In the process of building the course group, breaking through a single course model according to the characteristic of the intersection of the computer programming knowledge can combine and optimize the courses within the courses. It makes them complement and interact with each other, which reflects the importance of one course in the group for another. In conclusion, it forms a converged course system and obtains the 'one plus one more than two' effect.

\section{References}

[1] China Internet Network Information Center (CNNIC), the forty-first China Internet development statistics report, China Internet Information Center website: http://www.cnnic.net.cn, 2018.

[2] Wang Rui, Research on the teaching mode of mobile classroom under the information environment, Chinese Education Journal, vol. 12, pp. 59-62, 2015.

[3] Xiao Jinfang, and Shi Fang, Research and exploration of mixed learning model, Distance education in China, vol. 9, pp. 64-67, 2013.

[4] Hu Liru, Zhang Baohui, and Zhou Rong, Evolution trend of web-based learning platform from the perspective of software evolution, E-education Research, vol. 1, pp. 72-78, 2016.

[5] Shuang Liang Yao, Application Research of data mining in classification management of university achievement, Journal of Jiangsu University of Science and Technology: Social Science Edition, vol. 2, pp. 87-91, 2011.

[6] Edward F Crawley, Creating the CDIO Syllabus, a Universal Template for Engineering Education, 32nd ASEE/IEEE Frontiers in Education Conference, 2002.

[7] Edward F Crawley, The CDIO Syllabus a Statement of Goals for Undergraduate Engineering Education, www.cdio.org, 2009.

[8] Bankel J. Berggren K F. Blom K. et al. The CDIO syllabus: a comparative study of expected student proficiency, European Journal of Engineering Education, vol. 3, pp. 297-315, 2003.

[9] Hui Xian Li, on the construction of curriculum group in Colleges and Universities, Jiangsu Higher Education, vol. 6, pp. 73-75, 2006.

[10]Huang Yuchang, Exploration and practice of the construction of computer professional curriculum group in local universities, Journal of Shaoguan University, vol. 3, pp. 138-140, 2009. 